\title{
Representação de gestantes tabagistas sobre o uso do cigarro: estudo realizado em hospital do interior paulista
}

\author{
REPRESENTATION OF PREGNANT SMOKERS ON CIGARETTE USE: \\ A STUDY CARRIED OUT AT A HOSPITAL IN THE INTERIOR OF THE STATE OF SÃO PAULO
}

REPRESENTACIONES DE EMBARAZADAS FUMADORAS SOBRE USO DEL CIGARRILLO: ESTUDIO REALIZADO EN HOSPITAL CERCA DE LA CIUDAD DE SÃO PAULO

Marina Possato', Cristina Maria Garcia de Lima Parada², Vera Lúcia Pamplona Tonete ${ }^{3}$

1 Graduanda de Enfer-
magem, Faculdade
de Medicina de Botu-
catu da Universidade
Estadual Paulista
(UNESP), Bolsista de
Iniciação Científica
da FAPESP.
Piracicaba, SP, Brasil.
marina.possato@
bol.com.br
2 Professora Doutora
Assistente do Depar-
tamento de Enferma-
gem, Faculdade de
Medicina de
Botucatu, UNESP.
Botucatu, SP, Brasil.
cparada@fmb.unesp.br
3 Professora Doutora
Assistente do Depar-
tamento de Enferma-
gem, Faculdade de
Medicina de Botucatu,
UNESP.
Botucatu, SP, Brasil.
vtonete@fmb.unesp.br

\section{RESUMO}

Este estudo objetivou apreender as representações de gestantes tabagistas sobre o uso de cigarro. Utilizou-se como referencial teórico a Teoria das Representações Sociais. Para análise dos dados, construiu-se o Discurso do Sujeito Coletivo. Das $27 \mathrm{mu}-$ lheres entrevistadas, 18 possuíam primeiro grau completo, oito, o segundo grau completo e uma, ensino superior; 14 tinham união estável, seis eram casadas. Quatro temas emergiram: 1) o início do hábito de fumar: prática social e natural; 2) satisfação versus culpa; 3) uma bomba: efeitos do cigarro na gestação; 4) cessação: entre o querer e o poder. Apreendeu-se representação negativa do cigarro, considerado o pior dos vícios e potencial causador de complicações fetomaternas. O tabagismo foi representado de maneira preconceituosa, desconsiderando a existência e necessidade de tratamento. Emergiram dificuldades relativas à cessação, trazendo a necessidade de ajuda profissional, para informações, abordagem e tratamento adequados e apoio para que se alcance êxito.

\section{DESCRITORES}

Gravidez.

Tabagismo.

Tabaco.

\section{ABSTRACT}

This study sheds light on the smoking pregnant women's outlook on cigarette use. The Theory of Social Representations was used as a theoretical reference. For data analysis, the Collective Subject Discourse was constructed. Of the 27 women that were interviewed, 18 had finished elementary education, 8 had completed secondary education, and one had college level education; 14 had a stable union and 6 were married. Four themes emerged from the interviews: 1) starting to smoke: a natural, social practice; 2) satisfaction versus guilt; 3) shattering news: effects of smoking on pregnancy; and 4) quitting: between will and ability. Pregnant women revealed negative ideas about smoking, considering smoking the worst of addictions and a potential cause for complications to the fetus and the mother. Smoking was represented in a prejudicial manner, disregarding the existence of treatment and the need for it. Emerging difficulties were related to quitting, for which professionals, information and adequate approaches for treatment and support for achieving success are utmost necessities.

\section{KEY WORDS}

Pregnancy.

Smoking.

Tobacco.

\section{RESUMEN}

El objetivo fue aprehender representaciones de gestantes fumadoras sobre el uso del cigarrillo. Se utilizó la Teoría de las Representaciones Sociales. Para análisis de los datos, se construyó el Discurso del Sujeto Colectivo. De las 27 mujeres entrevistadas, 18 tenían el primero grado completo, 8 el segundo grado completo y una, la educación más alta; 14 tenían unión estable, 6 estaban casadas. Cuatro temas emergieron: 1) inicio del hábito de fumar: práctica social y natural; 2) satisfacción versus culpa; 3) una bomba: efectos de 1 cigarrillo en la gestación y 4) cesación: entre el querer y el poder. Se manifestaron los negativos del cigarrillo, considerado el peor de los vicios y potencial causador de complicaciones fetomaternas. El tabaquismo fue representado de manera prejuzgada, desconsiderando la existencia y necesidad de tratamiento. Emergieron dificultades hacia la cesación y necesidad de ayuda profesional para informaciones, abordaje y tratamiento adecuado y apoyo para que se alcance el éxito.

\section{DESCRIPTORES}

Embarazo.

Tabaquismo.

Tabaco. 


\section{INTRODUÇÃO}

A importância de se estudar o tabagismo na gestação decorre do fato de haver evidências de que o hábito de fumar neste período relaciona-se com o baixo peso ao nascer e com a restrição do crescimento intrauterino. Embora os dados sobre os efeitos relacionados aos partos prematuros não sejam consistentes, estudos brasileiros tendem a mostrar que os recém-nascidos de mães fumantes tenham riscos maiores de prematuridade, o mesmo ocorrendo com a mortalidade perinatal ${ }^{(1)}$. Assim, é possível que medidas que desencorajem o hábito de fumar durante a gestação possam reduzir o risco de complicações para o concepto e, conseqüentemente, contribuir para a redução da mortalidade perinatal.

Dentre as substâncias existentes no cigarro, a nicotina é a principal responsável pelos efeitos deletérios na gravidez, pois provoca a vasoconstrição dos vasos uterinos, com consequiente redução da disponibilidade de oxigênio para o feto $^{(2)}$

A importância do tabagismo na gestação é também numérica: estima-se que no Brasil uma em cada quatro gestantes seja fumante e, mesmo na vigência de programas específicos voltados à interrupção do fumo na gravidez, cerca de metade delas não consegue abandoná-lo( ${ }^{(1)}$.

Em consenso sobre abordagem e tratamento de fumantes, publicado pelo Ministério da Saúde do Brasil, os métodos de enfrentamento deste problema foram divididos em dois grupos: aqueles para os quais existem evidências sobre sua eficácia na cessação de fumar e aqueles que, embora preconizados, ainda carecem de evidências científicas sobre sua eficácia. Estão no primeiro grupo a abordagem cognitivo-comportamental e a farmacoterapia ${ }^{(3)}$.

A abordagem cognitivo-comportamental encontra-se dividida em: mínima, realizada em três minutos, consiste em perguntar, avaliar, aconselhar e preparar o fumante para que deixe de fumar; básica, leva de três a cinco minutos e consiste em perguntar, avaliar, aconselhar, preparar e acompanhar o fumante para que deixe de fumar e específica ou intensiva, realizada em ambulatório preparado para atender aos fumantes que querem deixar de fumar e não conseguem, aqueles que tiveram lapso ou recaída após as abordagens anteriores, os fumantes que não desejam parar de fumar e os não fumantes, que potencialmente poderão ajudar tabagistas que desejem abandonar o cigarro ${ }^{(3)}$.

Quanto a farmacoterapia, atualmente, o tabagismo é considerado uma doença crônica, devendo o fumante ser tratado como um dependente de drogas. O tratamento é variado, incluindo a reposição de nicotina e o uso de medicamentos que reduzem a vontade de fumar. Também deve ser considerada a terapia cognitiva e comportamental, ori- entações sobre o tabagismo, o apoio de amigos, familiares e profissionais da área da saúde ${ }^{(3)}$. Ressalta-se que a aceitação do fumante em todo este processo é essencial ao tratamento.

No segundo grupo, ainda carecendo de evidências científicas quanto a eficácia na cessação, estão a hipnose, a acupuntura, o feedback fisiológico, a aromaterapia, as fórmulas de ervas e os adesivos de lobélia ${ }^{(3)}$.

Tendo-se as próprias gestantes como sujeitos e buscando aproximação de suas percepções sobre a prática do tabagismo, através das entrevistas, mesmo sem o intuito, estas passam a ser um caminho ou início de uma abordagem cognitivo-comportamental mínima sobre o tema.

Considerando os malefícios do cigarro para a gestação e a dificuldade de abandonar o hábito neste período, o presente estudo propôs como objetivo central apreender as representações sociais de gestantes tabagistas sobre o uso do cigarro na gestação. No entanto, o trabalho procura demonstrar que existem formas de tornar a abordagem cognitivo-comportamental mais efetiva, talvez contribuindo com a diminuição do uso do cigarro durante a gravidez, bem como com a amortização do sofrimento e desespero de algumas gestantes.

\section{MÉTODO}

\section{Tipo de estudo e local de realização}

Optou-se por utilizar a abordagem qualitativa de pesquisa, a qual trabalha com o universo de significados, motivos, aspirações, crenças e atitudes, o que corresponde a um espaço mais profundo das relações e dos fenô$\operatorname{menos}^{(4)}$. O referencial teórico utilizado foi a Teoria das Representações Sociais, definida como saber do senso comum que permite compreender a formação do pensamento social ${ }^{(5)}$.

O estudo foi realizado em Botucatu, município localizado na região centro-sul do Estado de São Paulo, no Hospital das Clínicas da Faculdade de Medicina, serviço de nível terciário que oferece atendimento pré-natal a gestantes de alto risco e atendimento a pessoas tabagistas em ambulatórios específicos.

No Ambulatório de Obstetrícia são atendidas gestantes de alto risco, portadoras de hipertensão, cardiopatia, diabetes, alterações útero-placentárias, infecções genitais, gestação gemelar ou múltipla, entre outras.

\section{População do estudo}

Buscando indivíduos com vinculação significativa com a problemática, trabalhou-se com amostras intencionais e 
com critérios eminentemente qualitativos de coleta e processamento de dados ${ }^{(6)}$. Para a obtenção dos sujeitos, realizouse uma busca em prontuários de gestantes acompanhadas no Ambulatório de Obstetrícia, selecionando aquelas que possuíam o hábito de fumar e os dias de suas consultas de rotina. Em seguida, realizou-se o contato nos dias determinados, para a aplicação da entrevista, após consentimento, enquanto aguardavam pela consulta.

Foram incluídas no estudo gestantes que mantiveram o hábito de fumar durante toda a gestação, considerando-se apenas o consumo de cigarro do tipo industrializado, totalizando 27 mulheres.

Tendo-se as próprias gestantes como sujeitos e buscando aproximação de suas percepções sobre a prática do tabagismo, torna-se possível a elaboração de propostas de abordagem e tratamento mais coerentes e significativas para elas, que podem ser implementadas durante o atendimento prénatal, visando seu aconselhamento e apoio, tornando a abordagem cognitivo-comportamental mais efetiva, de forma a contribuir com a diminuição do uso do cigarro durante a gravidez, bem como amenizar o sofrimento de algumas gestantes.

\section{Coleta e análise dos dados}

Os dados foram colhidos por uma das pesquisadoras, no período de março a maio de 2004, através de entrevistas semi-estruturadas, realizadas individualmente em uma das salas do Ambulatório de Obstetrícia. Enquanto as gestantes esperavam por suas consultas de pré-natal, abordaram livremente o tema proposto, a partir das seguintes questões norteadoras: $\mathrm{O}$ que levou a senhora a fumar pela primeira vez?; Como a senhora acha que o cigarro age no seu corpo, agora que está grávida?; Durante seu atendimento pré-natal, alguém orientou a senhora sobre os efeitos do cigarro na sua gestação? e O que a senhora acha que precisa acontecer, para que uma pessoa pare de fumar?

Para análise dos dados, utilizou-se o Discurso do Sujeito Coletivo (DSC). Essa proposta consiste basicamente em analisar o material verbal coletado, extraindo-se dos discursos as Idéias Centrais - afirmação(ões) que permite (m) traduzir o essencial do conteúdo discursivo explicitado pelos sujeitos em seus depoimentos; as Expressões-Chave - transcrições literais de parte dos depoimentos, que permitem o resgate do que é essencial no conteúdo discursivo; a construção do Discurso do Sujeito Coletivo - realizado na primeira pessoa do singular, busca reconstruir com pedaços de discursos individuais, como um quebra-cabeça, tantos discursos-síntese quantos se julgue necessário para expressar o pensamento ou representação social de um grupo de pessoas sobre determinado tema e, por fim, a Ancoragem manifestação lingüística explícita de teorias, hipóteses, conceitos e ideologias existentes na sociedade e na cultura e internalizada no indivíduo autor do discurso, utilizada pelo enunciador para enquadrar uma situação específica ${ }^{(6)}$.

\section{Procedimentos éticos}

Este estudo seguiu as normas preconizadas pela Resolução nº 196/96, do Conselho Nacional de Saúde, relativa à pesquisa envolvendo seres humanos ${ }^{(7)}$, sendo desenvolvido após apreciação e aprovação do Comitê de Ética em Pesquisa da Faculdade de Medicina de Botucatu da Universidade Estadual Paulista. Observando os princípios éticos da pesquisa, as entrevistas foram realizadas após assinatura do Termo de Consentimento Livre e Esclarecido pelas gestantes tabagistas. Assim, atenderam-se aos requisitos mundialmente aceitos para pesquisas que envolvem seres humanos.

\section{RESULTADOS E DISCUSSÃO}

\section{Caracterização dos sujeitos}

As mulheres entrevistadas possuíam, em geral, baixa escolaridade, sendo que 18 delas haviam completado o ensino fundamental, oito haviam concluído o ensino médio e apenas uma possuía ensino superior. A faixa etária das gestantes foi assim distribuída: $18,6 \%$ delas tinham idade inferior a 20 anos, $70,4 \%$ possuíam idade entre 20 e 36 anos e $11 \%$ tinham mais de 36 anos. No grupo, havia 19 donas de casa, uma cozinheira, quatro faxineiras, uma secretária e duas balconistas. Do total de 27 mulheres, 14 tinham união estável e seis eram casadas. As sete gestantes solteiras moravam com os pais ou sozinhas. O grupo era composto por nove primigestas.

\section{As representações sociais de gestantes tabagistas sobre o hábito de fumar}

As questões norteadoras da entrevista permitiram apreender como foi, para as gestantes tabagistas, manter o hábito durante a gestação. Os resultados são apresentados subdivididos em 4 temas, que advindos das questões, expressam suas percepções sobre o hábito de fumar e vivências neste período: 1) o início do hábito de fumar: prática social e natural; 2) satisfação versus culpa; 3) uma bomba: os efeitos do cigarro na gestação e 4) cessação: entre o querer e o poder.

\section{O início do hábito de fumar: prática social e natural}

Um dos fatores que contribui para tornar a mulher tabagista é a massificação da propaganda, que associa ao cigarro beleza física e sucesso, estabelecendo uma representação social positiva desse hábito ${ }^{(8)}$. A representação do tabagismo como algo bonito, chique e que favorece a socialização, pode ser encontrada no DSC 1:

\footnotetext{
(Aprendi a fumar) na escola, ia fumar no banheiro, era gostoso fumar escondido, na farra, todo mundo fumando. Eu achava bonito, era chique fumar e depois comprar cigarro de marca pra mostrar[...].Não tinha esse negócio de que ia fazer mal tão explícito quanto hoje. Você fumava só um pouco e jogava, só pra fazer um social (DSC 1 - Idéia Central: Aprendi a fumar com minhas colegas na escola).
} 
Estudo sobre uso de drogas, realizado entre estudantes de enfermagem, revelou que os entrevistados recorriam ao uso de drogas para fugir de problemas ou auto-afirmação, por influência dos amigos ou curiosidade, entre outros ${ }^{(9)}$, o que também foi apreendido dos discursos das gestantes tabagistas. A influência de pais e amigos no início do hábito de fumar pode ser observada no DSC 2, onde o tabagismo é representado como algo natural, utilizado por todos os familiares:

Vendo os outros fumar: minha mãe, meu pai, meus irmãos, minha madrinha. O primeiro cigarro quem me deu foi minha própria mãe, que ofereceu pra experimentar, disse que era bom e aliviava se eu ficasse nervosa (DSC 2 - Idéia

Central: Na minha família todos fumavam).

Considerando-se os dois primeiros discursos, as representações apreendidas sobre os motivos que levam ao uso do cigarro parecem estar ancoradas no significado social que esta prática proporciona, em grupos de amigos e mesmo na família: o cigarro aproximando as pessoas, favorecendo vínculos, acalmando ansiedade.

\section{Satisfação versus culpa}

Como todas as outras dependências químicas, a nicotina envolve indivíduos que se encontram em alguma situação de vulnerabilidade. O dependente de nicotina acredita que o cigarro preenche vazios internos, é companheiro, ajuda a lidar com o estresse e o autocontrole, modula suas emoções, facilita interações sociais e eleva a sensação de segurança ${ }^{(10)}$. No presente estudo, as gestantes relatam sensação de alívio, companhia quando sozinhas e, principalmente, a diminuição do nervosismo com o uso do cigarro:

Sinto um alívio, relaxa o corpo, eu fico mais calma. É gostoso, tenho prazer de acender um cigarro, infelizmente. Me faz bem, é verdade, ele mata, mas faz bem. Quando eu estou nervosa e eu começo a fumar, tranqüiliza. O corpo parece que pede pra acender o cigarro e aí você tem uma satisfação[...].Quando eu estou sozinha eu gosto de fumar, até parece que tem alguém mais próximo, é uma coisa satisfatória, que acaba com o nervoso, com a raiva, fico mais sossegada. (DSC 3 - Idéia Central: Tenho prazer quando fumo).

O DSC 3 mostra que o uso do cigarro traz sensações prazerosas: acalma, tranqüiliza, satisfaz uma necessidade do corpo e até mesmo faz companhia. Entretanto, ao relacionarem a ocorrência da gestação em suas vidas com uso do cigarro, emergem sentimentos de culpa, dependência e medo das consequiências quanto a este hábito, conforme pode ser observado no DSC 4:

Agora que eu estou fumando um pouco mais e estou grávida, eu fico pensando, me sinto mal. Eu fumo com a consciência pesada, aquele remorso. Eu sinto uma coisa meio triste, fico magoada comigo mesma, um pouco culpada, com raiva, uma criminosa. Porque eu tento parar e não consigo: minha pressão abaixa, sinto tontura, calafrio, se eu ficar sentada num lugar e esperando eu já me sinto mal. Então, mesmo grávida estou fumando, sabendo que faz mal pra criança. Eu tenho muito medo de meu filho nascer com algum defeito. À noite eu rezo, peço: meu Deus, mande meu filho com saúde. Eu não vejo a hora que ele nasça, pra eu ver que está tudo certo, tudo tranqüilo, que está perfeito. Eu fico nessa agonia (DSC $\mathbf{4}$ - Idéia Central: Sinto-me uma criminosa).

No DSC 4 destaca-se a questão da abstinência, a qual é apreendida relacionada a manifestações físicas: hipotensão, tontura, calafrio, mal estar geral. A dificuldade do abandono também emerge deste discurso, apontando sentimentos como tristeza, mágoa, culpa, raiva e agonia, chegando ao extremo da gestante sentir-se criminosa por fumar.

As representações sobre a prática de fumar na gestação, contraditoriamente, estão permeadas por sentimentos positivos e negativos e parecem estar ancoradas na concepção do uso do cigarro como um vício, impossível de ser abandonado, capaz de trazer prazer e conseqüências negativas em situação de abstinência.

\section{Uma bomba: os efeitos do cigarro na gestação}

Neste estudo, abordou-se a associação entre tabaco e complicações gestacionais, na perspectiva das próprias gestantes tabagistas. Foi possível apreender que, para as entrevistadas, esta associação é clara. Inúmeras complicações, não necessariamente reais, foram citadas pelo grupo sobre os efeitos do cigarro, o que pode ser observado no DSC 5:

... não é saudável, faz mal pra saúde da gente e faz mais mal pro neném, prejudica muito. Os médicos falam, vi na televisão, no maço de cigarro e até lá no cartaz do posto de saúde, que o neném não ganha peso por causa do cigarro, pode nascer prematuro, passa mal, sente falta de ar, dá problema no pulmão, bronquite, asma, atrapalha 0 crescimento dele, dá má formação na criança, atraso mental, problema no coração, câncer no esôfago, garganta, boca e mais um punhado de coisa. Dizem que chega a causar a morte do bebê e eu posso ter descolamento da placenta e até doença mais grave. Posso também não engordar muito, porque o cigarro tira o meu apetite. É como um veneno, uma tremenda overdose que eu estou ingerindo. Até a pele da gente fica bem mais velha, me sinto muito cansada, com falta de ar, não consigo andar. Tenho tosse à noite e quando eu fumo meu coração dispara, inclusive, já estou com começo de câncer no útero, de tanto fumar. Do tempo que eu fumo, quantos anos de vida eu já devo ter perdido (DSC 5 - Idéia Central: Faz mal pra gente e para o neném).

$\mathrm{Na}$ literatura podemos encontrar, em linguagem científica, parte das consequiências citadas pelas gestantes, visto que o consumo de cigarro atua tanto dificultando a implantação da placenta - uma vez que as placentas de fumantes apresentam uma maior frequiência de necrose na decídua 
basal e que tal condição é uma possível causa de dificuldade de implantação e de descolamento precoce da placentaquanto interferindo no desenvolvimento normal de sua vascularização, com conseqüências deletérias para as trocas gasosas e de nutrientes entre a mãe e o feto ${ }^{(2)}$.

No DSC 5 o hábito de fumar na gestação é representado como algo extremamente danoso, como um veneno, capaz de provocar inúmeros problemas para a mãe e para o bebê.

Neste estudo, porém, o cigarro também foi representado como algo possivelmente inócuo, visto que as tabagistas não sentiam nada com o seu uso:

Tenho ouvido falar muito pouco, quase nada (sobre o cigarro). Não tenho nem idéia de como ele faz, mas eu não sinto nada e nem sou muito ligada, não presto muita atenção (DSC 6 - Idéia Central: Não tenho idéia de como 0 cigarro age).

Nos dias atuais, o fato das mulheres referirem desconhecer os efeitos do cigarro, pode significar uma opção, uma decisão de não querer conhecê-los. Esta negação tem o papel, inclusive, de preservá-las e isso emerge do DSC4, quando a gestante refere não prestar atenção quando questões relativas aos efeitos do cigarro são abordadas.

Os discursos que abordam as concepções das mulheres sobre os efeitos do cigarro na gestação revelam representações ancoradas em resultados de estudos científicos sobre os efeitos biológicos do tabagismo no corpo da gestante e do feto, que são freqüentemente divulgados pela mídia e pelos serviços de saúde e são reinterpretados pelo coletivo, conforme suas disponibilidade em absorvê-los como tal.

\section{Cessação: entre o querer e o poder}

Uma das questões do estudo buscou apreender a visão das gestantes sobre a abordagem profissional em relação ao tabagismo. Para a maioria, não passa de levantamento do problema. Esta constatação sugere que os profissionais de saúde têm se preocupado em identificar o problema, porém, pelo menos sob o ponto de vista das gestantes tabagistas, estes não têm se voltado com mais cuidado ao aconselhamento e às demais ações propostas nas diferentes abordagens contidas no Consenso anteriormente $\operatorname{citado}^{(3)}$, o que pode ser observado no DSC 7:

\footnotetext{
...só perguntaram se eu fumava e disseram que não é pra fumar, que faz mal. Em cada consulta me perguntam se eu parei. Mas é isso que eu não consigo. E na primeira consulta o médico não falou nada, só me pediu um monte de exames (DSC 7 - Idéia Central: Disseram que não é pra fumar).
}

Mais uma vez, transparece as idéias negativas que as gestantes fazem quanto ao uso do cigarro na gestação, o tabagismo como algo que faz mal. Associada a estas idéias negativas aparece outra questão importante: a dificuldade em abandonar seu uso.

Deve-se destacar que apesar do processo de capacitação de profissionais da área da saúde, desencadeado pelo Instituto Nacional do Câncer, em parceria com a Secretaria de Estado da Saúde de São Paulo, voltado ao desenvolvimento das abordagens mínima e intensiva ${ }^{(3)}$, é ainda recente o acúmulo de experiências nesta área no país e também o interesse dos profissionais de saúde com esse tipo de trabalho.

As referências às abordagens médicas, encontradas nos discursos, permitem caracterizá-las como abordagem mínima, principalmente, pelo aconselhamento dirigido às gestantes, conforme mostra o DSC 8:

Os médicos sempre falam que o cigarro faz mal, prejudica o neném, e eu sei. É tipo quando você assopra um monte de fumaça dentro de um saco e fecha, a fumaça fica em volta do neném. Pode nascer com problema no pulmão, prematuro e vai menos sangue pra ele. Falaram que o neném não ganha peso, dá câncer, que pode dar pressão alta na gravidez. E depois que ele nascer vai prejudicar a amamentação, porque a nicotina sai pelo leite e passa pro neném. Falam bastante, mis eu não guardo e as pessoas falam, começa me dar um nervoso e eu fumo mais ainda (DSC 8 - Idéia Central: As pessoas falam, fico nervosa e fumo mais).

Pelo DSC 8, pode-se confirmar que o uso cigarro na gestação é concebido como algo danoso, que dificulta a oxigenação, crescimento e alimentação do bebê. Porém, novamente transparece a angústia da gestante frente à dificuldade em abandoná-lo e uma certa negação, ao ser colocado que eu não guardo o que as pessoas falam sobre o cigarro.

Entre os serviços prestados pelo Hospital das Clínicas da Faculdade de Medicina de Botucatu, inclui-se o Ambulatório Antitabagismo. Neste, ocorre a abordagem intensiva, realizada especificamente em um ambulatório preparado para atender aos fumantes que querem deixar de fumar e não conseguem, sendo oferecido a cada fumante quatro sessões semanais de uma hora e meia e, após estas, retornos periódicos para acompanhamento. Apesar das dificuldades com a cessação, nenhuma gestante relatou utilizar esse Serviço, evidenciando uma possível falha na orientação profissional, talvez por não ter sido valorizada a dimensão da dificuldade de cessação ou mesmo pela ausência de qualquer aconselhamento durante a consulta.

É provável que os conteúdos ensinados nos cursos de graduação, através dos quais os profissionais têm tido acesso a esse tipo de informação, além da mídia e outros mecanismos de comunicação social, estejam ainda muito enfocados na repressão ao uso e ao usuário, resistindo à formulação de projetos de atuação que partam de uma compreensão histórico-social do uso de drogas, diminuindo o estigma sobre o usuário( ${ }^{(9)}$. 
Atualmente, o tabagismo está classificado internacionalmente no grupo de transtornos mentais e de comportamentos decorrentes do uso de substâncias psicoativas ${ }^{(3)}$. Sendo assim, o fumante deveria ser tratado como um dependente de drogas e, como tal, necessitando de auxílio médico e muitas vezes de remédios que reduzam a vontade de fumar e os sintomas de abstinência, além da necessidade de apoio psicológico, de amigos e familiares por um período longo. Os relatos das gestantes, porém, evidenciaram formas ineficientes de abordagem e ausência de acompanhamento efetivo.

Como já apresentado, recomenda-se que todas as gestantes e nutrizes tenham acesso a uma abordagem cognitiva comportamental para cessação do uso do fumo e, se necessário, encaminhamento para uma unidade que ofereça abordagem intensiva específica ${ }^{(3)}$. Nesse estudo, permeando os discursos, pode-se apreender um marcante desejo de uma forma de tratamento, acompanhamento e apoio, que diminuísse seus sentimentos de nervosismo e ansiedade para a cessação do fumo, conforme podemos observar no DSC 9:

\begin{abstract}
Só se tivesse um remédio, uma ajuda, um incentivo, porque sozinha eu não consigo. Eu tenho vontade, mas o cigarro é um vício, é horrível. Nós somos pior que drogados, eles têm hora certa pra fumar, nós não, fumamos em qualquer hora. E eu já viciei, qualquer coisinha que acontece, a primeira coisa é pegar no cigarro. Se tivesse alguma coisa que diminuísse a minha ansiedade, pra não me deixar nervosa. Talvez um tratamento, devia existir um lugar pra internar a gente, não deixar sair nem pro banheiro sem um acompanhante (DSC 9 - Idéia Central: Preciso de um tratamento).
\end{abstract}

$\mathrm{O}$ uso do cigarro chega, portanto, a ser representado como o pior dos vícios - aqui apontado como algo impossível de ser abandonado - talvez pela facilidade de acesso. Porém, novamente emerge dos discursos a dificuldade da cessação e o desespero das gestantes que não conseguem deixar de fumar. Defendem medidas extremas, inclusive de vigilância total. Abordam seu problema de forma dura, parecendo desacreditar, contraditoriamente, que este hábito tem e precisa de tratamento. Este preconceito e a necessidade de investimento pessoal para obter êxito também podem ser percebidos no DSC 10:

Precisa ter força de vontade pra parar de fumar, vergonha na cara mesmo. Porque todo mundo fica falando que o neném nasce com problema, a gente escuta por um ouvido e solta pelo outro. Tem que ter opinião forte, ajuda da pessoa que está do seu lado, isso é muito importante, e ficar pensando, talvez colocar no psicológico. Não precisa mais nada. Mas o cigarro me faz falta, nunca imaginei isso, ou só se não vendesse mais cigarro, mas daí a pessoa fica doida (DSC 10- Idéia Central: Preciso ter vergonha na cara).

O DSC 10 exemplifica as relações que as gestantes fazem entre o uso do cigarro na gestação e os problemas que pode causar ao bebê, mas, ao mesmo tempo, revela a percepção dessas mulheres sobre a dificuldade de parar de fumar trazendo, num primeiro momento, a responsabilidade para o nível pessoal e, em seguida, destacando a necessidade de apoio ou mesmo de medidas extremas, como a interrupção das vendas como alternativa para viabilizar a cessação. Porém, relaciona a falta do cigarro com loucura.

Outro grupo de mulheres afirma precisar de mais informação, ou de um susto que as motive a parar de fumar, apontando a necessidade de acontecimentos drásticos. Apesar de se encontrar na literatura que o enfoque repressivo que caracteriza os projetos de prevenção estão sendo cada vez mais criticados pelos estudos avaliativos ${ }^{(9)}$, este ainda é visto como necessário:

Se eu ver o que acontece, numa foto ou levar um susto. Acho que se eu soubesse, eu parava. Porque ouvir falar do problema não faz efeito, só se você tomar aquele susto. Não que eu queira, mas precisaria acontecer um infarto, uma trombose, um câncer na boca, alguma coisa pra eu parar. Eu fico com medo, mas fico fumando. Eu acho que a partir disso eu vou ter coragem de largar. Só que vai ser muito tarde (DSC 11 - Idéia Central: Preciso tomar um susto pra parar).

Considerando o DSC 11 pode-se confirmar que os problemas de saúde causados pelo hábito de fumar estão bastante introjetados nas concepções das gestantes tabagistas sobre esta prática. E, nestas concepções, novamente aparece a idéia de que somente submetidas a condições significativamente graves, poderiam abandonar este comportamento.

Pode-se apreender que as representações sobre o abandono do hábito de fumar que emergiram nos discursos das gestantes tabagistas, anteriormente apresentados, estão ancoradas na visão de que abandonar um vício depende apenas de esforço e vontade pessoal, sendo os que não conseguem êxito, fracos.

\section{CONSIDERAÇÕES FINAIS}

Apreendeu-se dos discursos clara representação negativa do cigarro na gestação: potencial causador de complicações fetais - especialmente relacionadas a problemas de crescimento, asfixia e prematuridade - e maternas, incluindo problemas placentários, cardiovasculares, respiratórios e câncer. Foi também representado como algo que pode levar à morte, como um veneno.

Analisando os discursos construídos a partir das falas das gestantes tabagistas, observa-se que a vontade de deixar de fumar é predominante. No entanto, demonstram dificuldades na cessação, mesmo considerando os efeitos do tabagismo.

Destacam-se, também, os conflitos vivenciados em relação ao hábito de fumar, em especial os sentimentos de culpa 
e tristeza. Frente a esses conflitos, surge a necessidade da ajuda profissional, que possa não só trazer informações, mas também a abordagem e o tratamento adequados, direcionando as gestantes a atividades que possam diminuir sua ansiedade.

Sabe-se que o tabagismo necessita de tratamento intensivo, sendo classificado como doença do grupo de transtornos mentais e dependência química. Porém, as gestantes representam o tabagismo como o pior dos vícios e, por isso, muitas vezes, o descreve de forma preconceituosa, desconsiderando que este hábito tem e precisa de tratamento. Além disso, tendem a sentirem-se as únicas responsáveis por este ato, comparando-se a criminosas.

Por todas estas questões, torna-se essencial o trabalho no período pré-natal com vistas à cessação do tabagismo, cabendo ao profissional de saúde apoiar as grávidas para que alcancem êxito neste processo e, para tanto, devese levar em conta a perspectiva das próprias gestantes,

\section{REFERÊNCIAS}

1. Victora CG. Intervenções para reduzir a mortalidade infantil préescolar e materna no Brasil. Rev Bras Epidemiol. 2001;4(1):3-69.

2. Aleixo Neto A. Efeitos do fumo na gravidez. Rev Saúde Pública [periódico na Internet]. 1990[citado 2006 mar. 12];24(5):[cerca de 6 p.]. Disponível em: http://www.scielo.br/scielo.php? script $=$ sci_arttext $\&$ pid $=$ S003489101990000500011\& lng $=$ pt\&nrm $=$ iso

3. Brasil. Ministério da Saúde. Secretaria Executiva. Secretaria de Atenção à Saúde. Coordenação do Instituto Nacional do Câncer. Abordagem e tratamento do fumante. Brasília; 2001.

4. Minayo MCS. Pesquisa social: teoria, método e criatividade. Petrópolis: Vozes; 1994.

5. Moscovici S. La psychanalyse son image et son public. Paris: Presses Universitaires de France; 1976.

6. Lefreve F, Lefreve AMC. O discurso do sujeito coletivo: uma nova abordagem metodológica em pesquisa qualitativa. Caxias do Sul: EDUCS; 2002. com o intuito de romper com as representações cristalizadas e limitantes, onde o problema é posto de forma intransponível.

No entanto, o ensino também deve contribuir para que profissionais da saúde tenham conhecimentos suficientes para alavancarem um projeto efetivo. De interessante implementação no período pré-natal, a abordagem pode começar com uma simples entrevista, visando o aconselhamento e apoio, ou mesmo com a formação de um grupo de gestantes tabagistas, com a realização de palestras educativas, bem como distribuindo materiais educativos, evoluindo talvez para uma terapia comunitária, onde as gestantes possam encontrar um espaço para troca de experiências e obtenção de apoio de pessoas que passam pelo mesmo problema. Dessa forma, talvez se possa contribuir com a diminuição do uso do cigarro durante a gravidez, bem como minimizar o sofrimento e desespero de algumas gestantes.
7. Conselho Nacional de Saúde. Resolução n. 196/96. Dispõe sobre diretrizes e normas regulamentadoras de pesquisas envolvendo seres humanos. Bioética. 1996; 4(2 Supl):15-25.

8. Torres BC, Cruz RCS, Albuquerque APS, Arraes CL. Tabagismo: é possível controlar? Rev Bras Med. 2001;58(6):394-7.

9. Campos FV, Soares CB. Conhecimento dos estudantes de enfermagem com relação às drogas psicotrópicas. Rev Esc Enferm USP. 2004;38(1):99-108.

10. Araujo AJ, Menezes AMB, Dorea AJPS, Torres BS, Viegas C AA, Silva CAR, et al. Diretrizes para cessação do tabagismo. J Bras Pneumol [periódico na Internet]. 2004 [citado 2006 mar. 12];30 Supl 2. Disponível em: http://www.scielo.br/ scielo.php?script=sci_arttext\&pid=S1806-37132004000800 002\&lng $=$ pt\&nrm $=\mathrm{iso} \& \operatorname{lng}=\mathrm{pt}$ 